\title{
DENTAL ANXIETY AMONG UNIVERSITY STUDENTS AND ITS CORRELATION WITH THEIR FIELD OF STUDY
}

\author{
Wael Mousa AL-OMARI ${ }^{1}$, Mahmoud Khalid AL-OMIRI ${ }^{2}$
}

1- BDS, MDentSci, PhD, Department of Restorative Dentistry, Faculty of Dentistry Jordan University of Science and Technology.

2- BDS., PhD, FDS, RCS (Eng.), Jor Board, Department of Restorative Dentistry, Faculty of Dentistry ,Jordan University of Science and Technology.

Corresponding address: Wael M. Al-Omari - Faculty of Dentistry - Jordan University of Science and Technology - PO BOX: 3030 - Irbid - Jordan - Fax: +962-2-295019 - e-mail: womari@just.edu.jo

Received: May 30, 2008 - Modification: August 31, 2008 - Accepted: October 7, 2008

\begin{abstract}
$O$

bjective: This study was designed to investigate the subjective ratings of dental anxiety levels among university students enrolled at Jordan University of Science and Technology. In addition, the present study aimed to explore the sources of dental anxiety and the impact of gender on the perceived dental anxiety and the correlation between field of study and dental anxiety level. Material and Methods: The Modified Corah Dental Anxiety Scale was used to measure dental anxiety among the study population. Six hundred subjects were recruited into the study from Jordanian undergraduate students from the faculties of Medicine, Engineering, and Dentistry. Results: Five hundred and thirty five complete questionnaires were returned, which accounts for a response rate of $89.2 \%$. The totals of the mean anxiety scores were the following: Medical students, $13.58 \%$; Engineering students, $13.27 \%$ and dental students, $11.22 \%$. About $32 \%$ of the study population has scored 15 or more. Dental students had the lowest percentage of those who scored 15 or more. Surprisingly, the medical students were responsible for the highest percentage of those who scored 15 or above. Although women demonstrated statistically higher total dental anxiety scores than men $(\mathrm{p}=0.03)$, the difference between both genders was small and could be clinically insignificant. The students were anxious mostly about tooth drilling and local anesthetic injection. Conclusion: Lack of adequate dental health education may result in a high level of dental anxiety among nondental university students in Jordan. Further studies are required to identify the correlates of dental anxiety among university students.
\end{abstract}

Key words: Anxiety scale. Dental. Medical students. Dental students. Engineering students.

\section{INTRODUCTION}

Dental anxiety is a recognized problem for both patients and dental health providers. Dental anxiety refers to patients' specific response towards dental situation-associated stress ${ }^{19}$. The presence of high levels of dental anxiety amongst dental care seekers yielded patients with negative attitudes towards dental treatment and rendered dental treatment more difficult to accomplish successfully ${ }^{4,16}$.

Anxious patients were considered among the most stressful situations a dentist might face ${ }^{1,12}$. Assessment of anxiety in such patients is a crucial factor for the success of their management.

Avoidance of dental care could be attributed to dental fear and anxiety in many patients t,9,23 $^{7}$. Dental anxiety might also affect patient-dentist relationship and obscure proper diagnosis of the actual dental problem ${ }^{8,25}$.

Taani $^{15}$ (2002) showed that the levels of dental anxiety were higher among Jordanian public school children than those from the private schools. Yet, dental fear and anxiety were found among the most reasons that underlie the irregular attendance in two thirds of the public school children and half of those from the private schools.

Many scales were developed in order to assess dental anxiety. Corah Dental Anxiety Scale was proven to be popular among dental researchers ${ }^{5}$. It is a simple, easy to score, short, valid and reliable test for dental visit-associated anxiety ${ }^{5,13,19,22}$. Humphris, Morrison and Lindsay ${ }^{21}$ (1995) provided a modified scale from the original Corah Dental Anxiety Scale. The Modified Dental Anxiety Scale was shown to be more comprehensive, highly valid and reliable, with a simpler and more consistent answering system. The Modified Dental Anxiety Scale will be, therefore, used to measure dental anxiety in the current study.

Lack of educational courses specialized in increasing dental awareness amongst non-dental university students in Jordan, in addition to shortage of information about correlation between field of study and dental anxiety levels in the dental literature have raised the idea of investigating the level of dental anxiety among the different student populations. This study was therefore designed to investigate the subjective ratings of dental anxiety levels among dental, 
medical and engineering Jordanian university students. In addition, the present study aimed to explore the sources of dental anxiety and the impact of gender on the perceived dental anxiety.

\section{MATERIAL AND METHODS}

Anxiety related to dental treatment was assessed by means of Corah's Dental Anxiety Scale (DAS). However, the modified version of DAS was used ${ }^{21}$ where an extra item has been included referring to the respondent's feelings toward local anesthetic injection with especial reference to the site of the injection, because the pain experienced with local anesthetic injections varies according to its location in the mouth ${ }^{14}$. Moreover, a simplified 5-point scaleanswering scheme was devised ranging from not anxious to extremely anxious.

The modified dental anxiety scale (MDAS) contains 5 multiple-choice items including the followings:

1 = If you went to your dentist for treatment tomorrow, how would you feel?

2 = If you were sitting in the waiting room, how would you feel?

$3=$ If you were about to have a tooth drilled, how would you feel?

4 = If you were about to have your teeth scaled and polished, how would you feel?

$5=$ If you were about to have a local anesthetic injection in your gum, how would you feel?

The scores for each of the 5 item responses were summed up to give an estimated value of dental anxiety. The questionnaire was distributed to the third to fifth year undergraduate dental, medical and engineering students at the Jordan University of Science and Technology. Students were personally approached in the classrooms by the authors at the end of their class. The students were informed about the study and all the points in the questionnaire were explained and clarified. Six hundred questionnaires were distributed to the students.

Descriptive statistics were obtained and the means, standard deviation and frequency distribution were calculated. Group comparisons were analyzed using twotailed Student's t tests as well as one-way analysis of variance (ANOVA) test. Multiple group comparisons were conducted using Tukey's Post Hoc test. Statistical significance was based on the probability values of $p=0.05$. Furthermore, as a total score of 15 or more almost indicates highly anxious patient $^{19}$, the frequencies of subjects with a score of 15 or more in the 3 student groups were also reported.

\section{RESULTS}

Out of the six hundred questionnaires distributed, 549 were returned. Fourteen questionnaires were completed partially and thus excluded from the study. The total number of the participants in the current study was therefore 535, which accounts for a response rate of 89.2 percent. The mean age of the subjects was $22.3 \pm 2.1$ years. The distribution of the participants according to gender and field of study is presented in Table 1.

Table 2 presents the means and standard deviations of individual items and total scores of the Modified Corah Dental Anxiety Scale with the results of one-way ANOVA analysis comparing the various groups based on the field of study. Out of the several anxiety scale items, the highest anxiety score (3.4) was given for tooth drilling (Item 3) and scored by the engineering students. The next most anxietyproducing item was the local anesthetic injection (3.32) which was scored by the medical students. However, for the items 1, 2, and 5, the only statistically significant differences were found between the dental and the medical students $(\mathrm{F}=7.92, \mathrm{P}=0.00 ; \mathrm{F}=4.69, \mathrm{P}=0.01, \mathrm{~F}=3.39, \mathrm{P}=$ 0.03 , respectively).

Dental students were significantly less anxious about scaling and polishing of teeth $(\mathrm{F}=8.99, \mathrm{P}=0.00)$ and about tooth drilling $(\mathrm{F}=19.58, \mathrm{P}=0.00)$ than other groups. However, there were no statistically significant differences between medical and engineering students in relation to these items (Table 2).

As expected, dental students scored the lowest total dental anxiety scores (Table 2) which were significantly lower than those scored by either medical or engineering students $(\mathrm{F}=14.13, \mathrm{P}=0.00)$.

Generally, in terms of total anxiety scores, women were relatively more anxious than men $(\mathrm{t}=-2.21, \mathrm{P}=0.03)$ (Table $3)$. Women were particularly more anxious than men concerning items related to waiting in the dentist's sitting room $(\mathrm{t}=-2.56, \mathrm{P}=0.01)$ and local anesthetic injection $(\mathrm{t}=$ $-2.62, \mathrm{P}=0.01)$. However, such gender variation was not significantly different when items related to going for dental visit tomorrow, having teeth drilled or having teeth scaled or polished were considered.

The numbers and percentages of subjects who had a total score of 15 or more are shown in Table 4 . About $32 \%$ of all

TABLE 1-The distribution of the subjects based on gender and the study field

\begin{tabular}{lccrc}
\hline Gender & Medical students & $\begin{array}{c}\text { Field of study } \\
\text { Engineering students }\end{array}$ & Dental students & Total \\
\hline Men & 98 & 84 & 83 & 265 \\
Women & 102 & 81 & 87 & 270 \\
Total & 200 & 165 & 170 & 535 \\
\hline
\end{tabular}


TABLE 2- Individual item and total dental anxiety scores according to the study field

\begin{tabular}{|c|c|c|c|c|}
\hline Questionnaire item & $\begin{array}{l}\text { Medical } \\
\text { students (SD) }\end{array}$ & $\begin{array}{l}\text { Engineering } \\
\text { students (SD) }\end{array}$ & $\begin{array}{l}\text { Dental } \\
\text { students (SD) }\end{array}$ & $\begin{array}{l}\text { P-value } \\
\text { (ANOVA) }\end{array}$ \\
\hline Go to dentist tomorrow & $2.31(1.27)^{a}$ & $2.05(1.36)$ & $1.79(1.01)^{a}$ & 0.00 \\
\hline $\begin{array}{l}\text { Sitting in dentist's } \\
\text { waiting room }\end{array}$ & $2.53(1.26)^{a}$ & $2.27(1.32)$ & $2.13(1.21)^{a}$ & 0.01 \\
\hline $\begin{array}{l}\text { About to have tooth } \\
\text { drilled }\end{array}$ & $3.26(1.41)^{a}$ & $3.4(1.56)^{b}$ & $2.51(1.26)^{a, b}$ & 0.00 \\
\hline $\begin{array}{l}\text { About to have teeth } \\
\text { scaled and polished }\end{array}$ & $2.16(1.22)^{a}$ & $2.41(1.42)^{b}$ & $1.85(0.98)^{a, b}$ & 0.00 \\
\hline $\begin{array}{l}\text { About to have local } \\
\text { anesthetic injection } \\
\text { in the gum }\end{array}$ & $3.32(1.43)^{a}$ & $3.13(1.54)$ & $2.93(1.39)^{a}$ & 0.03 \\
\hline Total score & $13.58(4.41)^{\mathrm{a}}$ & $13.27(4.47)^{b}$ & $11.22(4.47)^{a, b}$ & 0.00 \\
\hline
\end{tabular}

$\mathrm{SD}=$ Standard Deviation. * Values with same letters in each row are statistically different.

TABLE 3- Individual item and total dental anxiety scores according to gender

\begin{tabular}{llcc}
\hline Questionnaire item & Men (SD) & Women (SD) & P-value (t-test) \\
\hline Go to dentist tomorrow & $2.07(1.27)$ & $2.06(1.22)$ & 0.96 \\
Sitting in dentist's waiting room & $2.18(1.22)$ & $2.46(1.31)$ & 0.01 \\
About to have tooth drilled & $3.00(1.49)$ & $3.13(1.43)$ & 0.32 \\
About to have teeth scaled and polished & $2.06(1.24)$ & $2.21(1.23)$ & 0.15 \\
About to have local anesthetic injection in the gum & $2.97(1.47)$ & $3.30(1.43)$ & 0.01 \\
Total score & $12.29(4.75)$ & $13.17(4.51)$ & 0.03 \\
\hline
\end{tabular}

$\mathrm{SD}=$ Standard Deviation

TABLE 4- Number and percentage of subjects scoring 15 or more on the modified dental anxiety scale according to gender and field of study

\begin{tabular}{|c|c|c|c|c|c|c|}
\hline \multirow[b]{2}{*}{ Field of study } & \multicolumn{2}{|c|}{ Men } & \multicolumn{2}{|c|}{ Women } & \multicolumn{2}{|c|}{ Total } \\
\hline & $\mathbf{N}$ & $\%$ & $\mathbf{N}$ & $\%$ & $\mathbf{N}$ & $\%$ \\
\hline Medical students & 37 & 13.9 & 46 & 17.0 & 83 & 15.5 \\
\hline Engineering students & 29 & 10.9 & 26 & 9.6 & 55 & 10.3 \\
\hline Dental students & 11 & 4.2 & 21 & 7.8 & 32 & 6.0 \\
\hline
\end{tabular}


subjects have scored 15 or more. Surprisingly, medical students were found to be the most frequent among those who scored 15 or above.

\section{DISCUSSION}

This study revealed that dental students do have lower levels of dental anxiety than their engineering and medical counterparts $(\mathrm{P}<0.01)$. The mean total scores for the MDAS showed that severe dental anxiety was mostly associated with drilling and intraoral local anesthetic injection.

A total score of 15 or more indicates a highly anxious patient ${ }^{19}$. Surprisingly, the medical students showed the highest total anxiety scores and the greatest percentage of subjects scoring 15 or more. The engineering students were already expected to score the highest anxiety scores as they do not receive health or dental awareness education, whilst the medical students are supposed to be more familiar with stress management related to health measures. However, some of the highly anxious patients may avoid showing their anxiety in order not to interfere with the dentist's procedure. Thus, the dentist should be aware of the patient's possible adverse reaction or distress ${ }^{19,21}$.

However, when the data are critically appraised, statistically significant difference between groups related to total anxiety scores or the scores of individual items of the anxiety scale could be seriously misleading and possibly do not always reflect an actual clinical significance. The differences in many situations were noticeably small, though statistically significant. This could be attributed to the fact that the sample size is large, which added to the power of the study and revealed even the minor statistical differences between the groups. Thus conclusions made on actual differences in numbers and on absolute statistical significance should be drawn with caution.

Lack of dental health education might result in patients' fear and anxiety which in turn might end with poor patient compliance and attitudes. This will make it more difficult to manipulate patients and yield difficult patients and thus increase the levels of dental profession-related stress ${ }^{1,12}$.

Assessing the level of patient anxiety before commencing the dental treatment may offer invaluable insight into the probable patient attitudes and behavior towards the dental treatment. This information will be further utilized in developing the best strategies to manage patient anxiety.

Health-related behavior depends on oral health knowledge ${ }^{14}$. In Jordan, only students related to the dental field receive adequate dental health education as it is an integral part of their curriculum. Jordanian schools and universities pay little attention to the dental health education of their students. Students not related to the dental field receive little, if any, dental health education and their curricula lack such courses. Since the dental health education is generally ignored in the pre-university stage, medical and engineering students still possess the same ideas about dentistry and dental care at the university. On the other hand, dental field-related students do have the chance to formulate new and better ideas and understanding of the dental health care and thus will have the chance to develop a better dental behavior.

For the above mentioned reasons, the dental treatment will still be considered mysterious and stressful for the nondental students while the dental students will feel better during the dental treatment. This could partly explain the relatively higher scores of dental anxiety among the nondental students compared to their dental peers.

Irregular dental attendance may play a major role in increasing the levels of dental anxiety ${ }^{15,23}$. If this is added to the lack of dental health education in Jordan, the high levels of dental anxiety could be explained and clearly demonstrated among the non-dental students.

Dental anxiety was related to personality and psychological status ${ }^{3,17,18}$. This might form the bases for explaining the presence of higher levels of dental anxiety among women as well as medical students in this study.

Female students were found to have higher levels of dental anxiety in all groups and they were more anxious about waiting in the sitting room and taking anesthetic injections. This corroborated the results from previous studies that showed higher levels of dental anxiety among women ${ }^{11,21,24}$. This finding might be explained on the basis that women have higher levels of neuroticism than men and that anxiety is positively associated with neuroticism ${ }^{9,10,20}$. However, in the current study, the statistically significant difference between men and women was marginal and the difference in anxiety scores for both genders was minimal (Men 12.29\%, Women 13.17\%). Therefore, it could be inferred that statistical significance might not be necessarily interpreted as a clinical one.

Medical students might be prone to have higher levels of neuroticism, due to their courses and stressful field of study $^{2}$ and thus demonstrate higher levels of dental anxiety than engineering students. On the other hand, although dental students are leading stressful courses and profession they are yet still exposed to better dental health education and knowledge and thus develop favorable dental behavior. Presence of suitable dental health education and knowledge seems to be capable, to some extent, of overruling the effect of stress and personality factors on dental anxiety among dental students.

The control of dental anxiety might be aided via good dental health education, regular dental visits, good patientdentist relationship and suitable communication with the patients $^{6}$. For a successful dental treatment, a gentle, supportive, professional, sympathetic, quiet and more considerate approach should be followed when managing patients with dental anxiety. On their first visit, patients should be dealt with more sensitively in order to avoid increasing their anxiety and thus avoid their repulsion to the dental care ${ }^{9}$.

In view of the current available data, it appears that further dental health education measures are required to be applied among the Jordanian non-dental university students and the population in general in order to control the levels of dental anxiety and thus improve patient dental attitudes 
and compliance.

Suitable standards of dental health knowledge and education could overcome the negative effects of personality and reduce dental anxiety. Dental health care providers should receive training in the management of dental anxiety. Interception of dental anxiety at early stages will reduce the chance of resistant dental anxiety and fear which are difficult to deal with in the dental clinic.

The importance of dental health education can not be overemphasized in the reduction and control of dental anxiety. Pre-university as well as non-dental university curricula should include dental health education in order to help reduction of dental anxiety among the population.

\section{CONCLUSIONS}

It was concluded that dental students had the lowest anxiety scores. Medical students were very anxious about dental treatments. Women demonstrated higher dental anxiety scores than men $(\mathrm{p}=0.03)$. The students were mostly anxious about tooth drilling and local anesthetic injection.

Although the current study utilized the modified anxiety scale and investigated the levels of dental anxiety among university students from different fields of study and the sample size was representative and large, further studies are required to investigate the effect of various correlates on dental anxiety. Additionally, the statistical significance should not be always inferred as clinical one.

\section{REFERENCES}

1-Aartman IH, Jongh A, Van Der Meulen MJ. Psychological characteristics of patients applying for treatment in a dental fear clinic. Eur J Oral Sci. 1997; 105:384-8.

2 -Ashley FP. Role of dental health education in preventive dentistry. In: Murray JJ, Ed. Prevention of dental disease. Oxford: Oxford University Press; 1996. p.406-14.

3- Cooper CL, Watts J, Kelly M. Job satisfaction, mental health and job stressors among general dental practitioners in the UK. Br Dent $\mathrm{J}$. $1987 ; 124: 77-81$

4- Corah NL, Gale EN, Illig SJ. Assessment of a dental anxiety scale. J Am Dent Assoc.1978;97:816-9.

5- Corah NL. Development of a dental anxiety scale. J Dent Res. $1969 ; 48: 596$

6- Dohrenwend BP, Dohrenwend BS. Social and cultural influences on psychopathology. Annu Rev Psychol. 1974;25:417-23.

7- Eli I. Dental anxiety: a cause for possible misdiagnosis of tooth vitality. Int Endod J. 1993;26:251-3.

8- Frazer M, Hampson S. Some personality factors related to dental anxiety and fear of pain. Br Dent J. 1988;165:436-9.

9- Freeman R. A psychodynamic theory for dental phobia. Br Dent J. 1998; $184: 170-2$.

10- Freeman R. Communicating effectively: some practical suggestions. Br Dent J. 1999;187:240-4.
11- Humphris GM, Morrison T, Lindsay SJ. The modified dental anxiety scale: validation and United Kingdom norms. Community Dent Health. 1995; $12: 143-50$.

12- Humphris GM, Peacock L. Occupational stress and job satisfaction in the community dental service of North Wales: a pilot study. Community Dent Health. 1993;10:73-82.

13- Kent G. Anxiety, pain and type of dental procedure. Behav Res Ther. $1984 ; 22: 465-9$

14- Lautch H. Dental phobia. Br J Psychiatr. 1971;119:151-8.

15-Lindsay SJ, Humphris G, Barnby GJ. Expectations and preferences for routine dentistry in anxious adult patients. Br Dent J. 1987;163:1204.

16- Locker D, Liddlle A, Burman D. Dental fear and anxiety in an older adult population. Community Dent Oral Epidemiol. 1991;19:120-4.

17- Locker D, Shapiro D, Liddell A. Negative dental experiences and their relationship to dental anxiety. Community Dent Health. 1996;13:8692

18- Moore R, Brødsgaard I, Birn H. Manifestations, acquisition and diagnostic categories of dental fear in a self-referred population. Behav Res Ther. 1991;29:51-60.

19- Roy-Byrne P P, Milgrom P, Tay KM. Psychopathology and psychiatric diagnosis in subjects with dental phobia. J Anx Dis. 1994;8:19-31.

20- Stecher T. Well-being in an academic environment. Med Edu. 2004;38:465-78.

21- Taani DQ. Dental attendance and anxiety among public and private school children in Jordan. Int Dent J. 2002;52:25-9.

22- Taani DQ. Dental fear among a young adult Saudian population. Int Dent J. 2001;51:62-6.

23- Ter Horst G, de Wit CA. Review of behavioral research in dentistry 1987-1992: dental anxiety, dentist-patient relationship, compliance and attendance. Int Dent J. 1993;43:265-78.

24- Weinstein P, Smith TA, Bartlett RC. A study of the dental studentpatient relationship. J Dent Res. 1973;52:1287-92.

25- Woolgrave J, Cumberbatch G. Dental anxiety and regularity of dental attendance. J Dent. 1986;14:209-13. 